\title{
Aerosol Lidar observations and model calculations of the Planetary Boundary Layer evolution over Greece, during the March 2006 Total Solar Eclipse
}

\author{
V. Amiridis ${ }^{1}$, D. Melas ${ }^{2}$, D. S. Balis ${ }^{2}$, A. Papayannis ${ }^{3}$, D. Founda ${ }^{4}$, E. Katragkou ${ }^{2}$, E. Giannakaki ${ }^{2}$, R. E. Mamouri ${ }^{3}$, \\ E. Gerasopoulos ${ }^{4}$, and C. Zerefos ${ }^{5}$ \\ ${ }^{1}$ Institute for Space Applications and Remote Sensing, National Observatory of Athens, Athens 15236, Greece \\ ${ }^{2}$ Laboratory of Atmospheric Physics, Aristotle University of Thessaloniki, Thessaloniki 54124, Greece \\ ${ }^{3}$ National Technical University of Athens, Athens 15780, Greece \\ ${ }^{4}$ Institute for Environmental Research and Sustainable Development, National Observatory of Athens, 15236 Athens, Greece \\ ${ }^{5}$ Laboratory of Climatology, University of Athens, Athens 15784, Greece
}

Received: 10 August 2007 - Published in Atmos. Chem. Phys. Discuss.: 14 September 2007

Revised: 26 November 2007 - Accepted: 3 December 2007 - Published: 20 December 2007

\begin{abstract}
An investigation of the Planetary Boundary Layer (PBL) height evolution over Greece, during the solar eclipse of 29 March 2006, is presented. Ground based observations were carried out using lidar detection and ranging devices and ground meteorological instruments, to estimate the height of the mixing layer (ML) before, during and after the solar eclipse in northern and southern parts of Greece exhibiting different sun obscuration. Data demonstrate that the solar eclipse has induced a decrease of the PBL height, indicating a suppression of turbulence activity similar to that during the sunset hours. The changes in PBL height were associated with a very shallow entrainment zone, indicating a significant weakening of the penetrative convection. Heat transfer was confined to a thinner layer above the ground. The thickness of the entrainment zone exhibited its minimum during the maximum of the eclipse, demonstrative of turbulence mechanisms suppression at that time. Model estimations of the PBL evolution were additionally conducted using the Comprehensive Air Quality Model with extensions (CAMx) coupled with the Weather Research and Forecasting model (WRF). Model-diagnosed PBL height decrease during the solar eclipse due to vertical transport decay, in agreement with the experimental findings; vertical profiles of atmospheric particles and gaseous species showed an important vertical mixing attenuation.
\end{abstract}

\section{Introduction}

Solar eclipses provide a unique opportunity for studying various atmospheric phenomena, when the incoming solar radi-

Correspondence to: V. Amiridis

(vamoir@space.noa.gr) ation is sharply turned off and on during these events. Since Planetary Boundary Layer (PBL) is the region closer to the earth's surface, where mass, energy and momentum transport towards other parts of the atmosphere takes place via turbulence process, a change in the radiative heating or cooling will be felt firstly in the PBL before it reaches the free atmosphere.

During a normal day overland, a convective atmospheric boundary layer (CBL) develops, reaching a quasi-steady state in the afternoon, with a mixed layer from the ground up to the interfacial layer with the free atmosphere, a region of strong thermal inversion. Generally, the CBL afternoon/evening transition is marked before sunset by a development of a surface inversion related to surface cooling. The CBL, often called the residual layer after sunset, becomes neutral above that stable layer. After sunrise, the stable layer is destroyed and a new mixing layer develops. These phenomena have been extensively studied experimentally and theoretically in steady state (Stull, 1988), but the evolution during transitions is still not so well known. During a solar eclipse, the two transition situations are reproduced, however with time scales much shorter than those of the normal diurnal cycle, still providing an excellent chance for investigating the mechanisms driving the PBL evolution.

In the few studies dealing with PBL during solar eclipses, important findings are reported. Antonia et al. (1979), examined the velocity and temperature fluctuations during a solar eclipse (23 October 1976) of $80 \%$ totality over Delinquin, Australia, to determine the Atmospheric Surface Layer (ASL) response on the changes of ground heat-flux. It was found that during the eclipse the surface layer turbulence approximately follows a continuum of equilibrium states in response to stability changes brought about by the change in

Published by Copernicus Publications on behalf of the European Geosciences Union. 
surface heat flux. This point has been also illustrated by Eaton et al. (1997). The authors showed the eclipse effects on the PBL over a desert site in New Mexico, USA (94\% totality), using data acquired near the ground and in the surface layer with a frequency-modulated continuous wave (FMCW) radar. They report that during the eclipse maximum, the sensible heat-flux and the radiation flux were affected, the turbulence was reduced and the air refractive index structure constant decreased dramatically.

Another close study of the PBL dynamics during the 11 August 1999 eclipse was performed with U1tra High Frequency Radio Acoustic Sounding System (UHFRASS) radar, sodar and an instrument mast by Girard-Ardhuin et al. (2003). It was found that the eclipse induces a clear response in the atmosphere with a time lag of 15 to $30 \mathrm{~min}$. Boundary Layer experiments conducted over India during the total solar eclipse of 16 February 1980 (Narasimha et al., 1982; Sethuraman, 1982) and also during the total solar eclipse of 1995 (Arulraj et al., 1998), witnessed a decrease in near surface temperature, wind speed and also the changes in atmospheric stability following the solar eclipse.

There are also evidences of oscillations in ASL parameters over India (Dolas et al., 2002) following the total eclipse event of 11 August 1999. However, that particular event occurred near sunset thus masking the absolute effects of the eclipse on the meteorological variables. The dynamics of the PBL during the solar eclipse of 11 August 1999, over Bulgaria were studied with an aerosol backscatter lidar by Kolev et al. (2005). Data used in this study demonstrate that the solar eclipse affects the meteorological parameters of the atmosphere near the ground, the ozone concentration and the height of the mixing layer. During the period encompassed by the beginning of the solar eclipse (at 12:36 LT) and its maximum (reached at 14:03 LT), the ML height has increased from $1600 \mathrm{~m}$ to $1900 \mathrm{~m}$; from 14:03 LT to $15: 27 \mathrm{LT}$ when the eclipse ended, the ML height decreased down to $1200 \mathrm{~m}$ as a result of the diminished irradiation of the Earth's surface. This behaviour was followed by another increase in the ML height.

The aim of this paper is to study the PBL height response to the March 2006 solar eclipse, by analysing the aerosol structure of the atmosphere. Two backscatter lidars, as well as additional meteorological surface and vertical profile data (radiosondes) are used to document and analyse the dynamic and thermodynamic response of the lower atmosphere to the sudden change of the incoming solar radiation. For the first time during a solar eclipse, lidar data from two sites (where different meteorological conditions were prevailed) are combined for the study of the PBL development. The analysis of the lidar data is complemented by numerical simulations with the CAMx model.

\section{Instrumentation and methods}

\subsection{Lidar systems and methodologies}

The lidar system of Aristotle University of Thessaloniki AUTH $\left(40.5^{\circ} \mathrm{N}, 22.9^{\circ} \mathrm{E}\right)$, is designed to perform continuous measurements of suspended aerosols particles in the PBL and the lower free troposphere. It is based on the second and third harmonic frequency of a compact, pulsed $\mathrm{Nd}$ :YAG laser, emitting simultaneously pulses of 120 and $150 \mathrm{~mJ}$ output energy at 355 and $532 \mathrm{~nm}$, respectively, with a $10 \mathrm{~Hz}$ repetition rate. The receiving telescope has a primary diameter of $500 \mathrm{~mm}$ and an equivalent focal length of $5000 \mathrm{~mm}$. Photomultiplier tubes (PMTs) are used to detect the received lidar signals in the analog and the photon counting mode, with a corresponding raw range resolution of $7.5 \mathrm{~m}$ (Balis et al., 2000; Amiridis et al., 2005).

The lidar system of National Technical University of Athens - NTUA $\left(37.9^{\circ} \mathrm{N}, 23.8^{\circ} \mathrm{E}\right)$, is also based on the second and third harmonic frequency of a compact pulsed $\mathrm{Nd}$ :YAG laser, which emits simultaneously pulses of 80 and $130 \mathrm{~mJ}$ output energy at 355 and $532 \mathrm{~nm}$, respectively, with a $10 \mathrm{~Hz}$ repetition rate. The optical receiver is a Cassegrainian reflecting telescope with a primary mirror of $300 \mathrm{~mm}$ diameter and a focal length of $600 \mathrm{~mm}$, directly coupled, through an optical fiber, to the lidar signal detection box (Papayannis and Chourdakis, 2002). The detectors are operated both in the analog and photon-counting mode and the spatial raw resolution of the detected signals is $15 \mathrm{~m}$.

Both lidar systems are equipped with a Raman channel working at $387 \mathrm{~nm}$ (atmospheric $\mathrm{N}_{2}$ channel) for night-time operation. The lidar systems of AUTH and NTUA operate within EARLINET project (European Aerosol Lidar Network) since 2000 and both operation and the algorithms implemented were successfully intercompared with other EARLINET lidar systems as reported by Matthias et al. (2004); Boeckmann et al. (2004) and Pappalardo et al. (2004).

Averaging time of the lidar profiles during the March 2006 solar eclipse case, was of the order of $3 \mathrm{~min}$ for Thessaloniki and $1 \mathrm{~min}$ for Athens, corresponding to 2000 and 1000 laser shots, respectively. The final spatial resolution of the rangesquared-corrected signal (RSCS) at both stations was $15 \mathrm{~m}$. The determination of the ML height distribution by lidar during the eclipse is the first step in our analysis. In general, the optical power measured by a lidar system is proportional to the signal backscattered by particles and molecules present in the atmosphere. Using aerosol particles as a tracer, one can determine the top of the ML as the height where the lidar signal profile exhibits a discontinuity between the mixed layer and free troposphere. The method used to retrieve the ML height in this study is based on the detection of the drop off in the RSCS signals at the interface between the free troposphere and the mixed layer. 
Following the methods analytically presented by Menut et al. (1999) and Flamant et al. (1997), we have used the minimum value of the filtered first order derivative of averaged RSCS profiles with respect to the altitude to define the top of the mixed layer, which coincides with the base of the entrainment zone. The depth of the entrainment zone is defined here as the height difference between the derivative minimum and the lowest data point defined by that negative peak (Flamant et al., 1997). The gradient method can be quite complicated because the minimum cannot be well defined or several minima might exist over an extended height range. Therefore, one should also study, simultaneously, the temporal distribution of the aerosol layers and of the altitude of the minima.

\subsection{Modeling}

The regional air quality model simulations were performed with the Comprehensive Air quality Model with extensions (CAMx) version 4.40. Within the scope of this campaign, CAMx ran with coarse grid spacing over Greece, in a spatial resolution of $10 \times 10 \mathrm{~km}$ and two fine nests with higher resolution $(2 \times 2 \mathrm{~km})$ over Greater Athens and Thessaloniki area, respectively. The domain's vertical profile contained 15 layers of varying thickness. Layer 1 was $22 \mathrm{~m}$ deep and subsequent layer depths increased with height. The uppermost layer was $1.5 \mathrm{~km}$ thick and extended to about $8 \mathrm{~km}$. The meteorological fields were derived from the Weather Research and Forecasting (WRF version 2.1.2) Model, developed at the National Center for Atmospheric Research (NCAR), operated by the University Corporation for Atmospheric Research (UCAR). The first model domain covered the Balkan area $(55 \times 55$ grid points with $30 \mathrm{~km}$ resolution), the second domain covered Greece (nested domain with $121 \times 121$ grid points and $10 \mathrm{~km}$ resolution) and the two domains with finer resolution $(2 \times 2 \mathrm{~km})$ covered the two measuring sites (Athens; Thessaloniki). The vertical profile contained 31 vertical layers extending to $18.5 \mathrm{~km}$.

Anthropogenic and biogenic emissions were compiled for a coarse master domain covering Greece $(98 \times 108$ cells, $10 \times 10 \mathrm{~km})$ and for the two nested grids with finer resolution $(2 \times 2 \mathrm{~km})$. Emission data for gaseous pollutants (NMVOC, $\left.\mathrm{NOx}, \mathrm{CO}, \mathrm{SO}_{2}, \mathrm{NH}_{3}\right)$ and particulate matter $\left(\mathrm{PM}_{10}\right)$ were estimated for different anthropogenic emission source sectors such as the transport, power plants, the industrial and the central heating sector. Anthropogenic emissions of the neighbouring countries (Albania, Bulgaria, Turkey) were taken from the EMEP emission database. Diurnal biogenic emissions for Greece and neighbouring countries were calculated for every month of the year following the EMEP/CORINAIR methodology (Poupkou et al., 2004). All emissions are ejected in the first model level.

Three days of simulation were regarded as "spin-up" time (26-28 March 2006) in order to eliminate the effect of initial conditions. Initial and boundary conditions corresponded to concentrations of clean air. The chemistry mechanism invoked was Carbon Bond version 4 (CB4). Photolysis rates were derived for each grid cell as a function of five parameters: solar zenith angle, altitude, total ozone column, surface albedo, and atmospheric turbidity. Both meteorological and chemical models have been modified accordingly to reproduce the eclipse event (for more details see Founda et al., 2007; Zanis et al., 2007). In order to account for the photochemical changes of the atmosphere during the eclipse, photolysis rates in the chemical model were adjusted during the period 09:30-12:00 UTC using a space- and time-dependent factor. Thermodynamic changes were introduced into the chemical model with a set of eclipse-affected meteorological input.

\section{Results and discussion}

With the objective of studying the changes in the PBL structure due to the sudden attenuation of radiation, field experiments were conducted over Athens and Thessaloniki close to the totality path of the solar eclipse of 29 March 2006. During the solar eclipse, Athens and Thessaloniki experienced $84 \%$ and $74 \%$ obscuration, respectively. The partial eclipse for both sites took place between 09:36-12:04 UTC, with the maximum phase occurring at 10:50 UTC. A general description of the field experiments and the local eclipse circumstances over Greece can be found in (Gerasopoulos et al., 2007).

\subsection{Lidar measurements}

Figure 1 presents the time cross-section of the first derivative of the RSCS at $532 \mathrm{~nm}$, measured by the backscatter lidars in Thessaloniki (a) and Athens (b) on 29 March 2006. In Fig. 1a, the evolution of the ML height along with the thickness of the entrainment zone is shown for Thessaloniki. In the morning and until 09:30 UTC when the eclipse began, the height of the ML in Thessaloniki grew up to about $700 \mathrm{~m}$. ML heights below $400 \mathrm{~m}$ would not been detected by AUTH's lidar due to laser beam and telescope field-of-view overlap limitations (Balis et al., 2002). Between first contact (09:36 UTC) and maximum of the eclipse (10:50 UTC), $74 \%$ obscuration), the ML height declined to about $550 \mathrm{~m}$. At 11:00 UTC low clouds were formed over Thessaloniki at an altitude of approximately $250 \mathrm{~m}$ and remained until 11:50 UTC, inhibiting aerosol lidar measurements. During this period, the lidar retrieved cloud base height is presented in Fig. 1a. After 11:50 UTC, the ML height was measured at $600 \mathrm{~m}$ and remained at this altitude until 12:50 UTC, followed by a small fall of $50 \mathrm{~m}$ between 12:50 and 13:20 UTC. During the above time periods, the upper boundary of the entrainment zone exhibits similar behaviour. The entrainment zone thickness ranged between $80 \mathrm{~m}$ and a minimum of $20 \mathrm{~m}$ during the total phase. This indicates a significant 

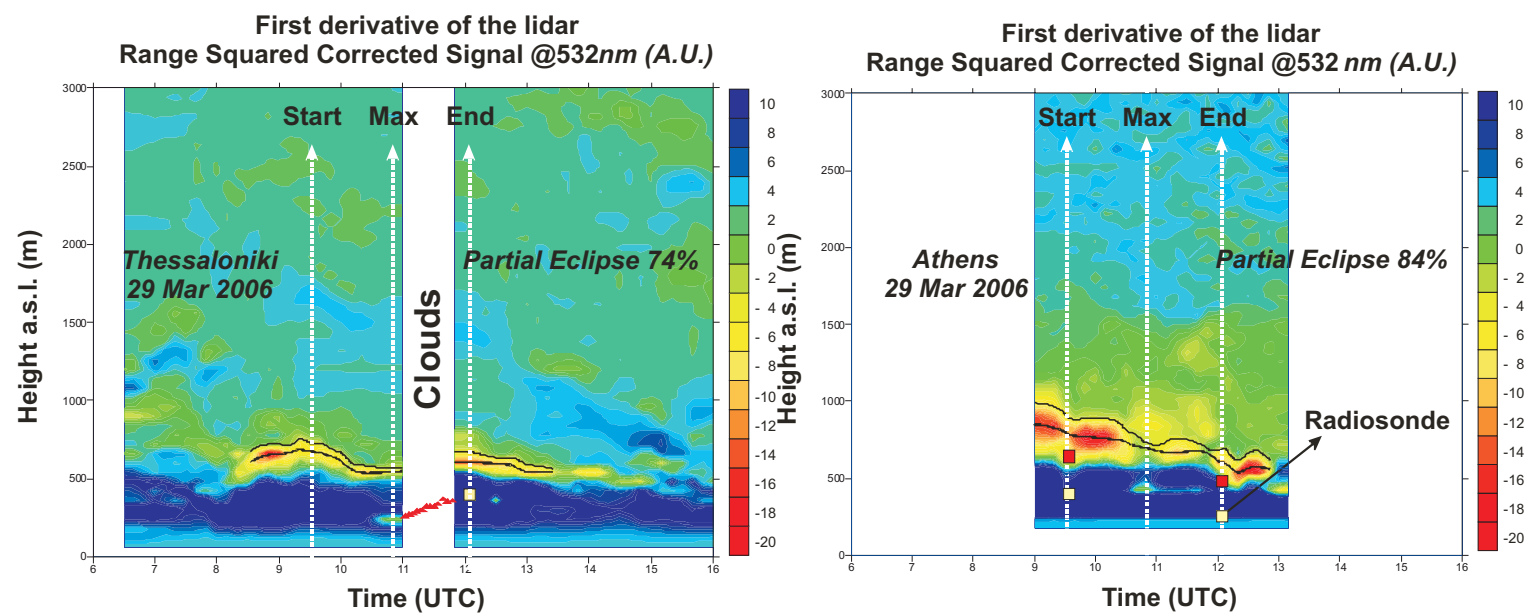

Fig. 1. Time-height cross section of the first derivative of the range squared corrected lidar signal at $532 \mathrm{~nm}$ (in arbitrary units - A.U.) at Thessaloniki (a) and Athens (b) measured on 29 March 2006. The upper and lower limits of the entrainment zone are demonstrated with the thin and bold solid line, respectively, the latter representing the evolution of the ML height. Red triangles correspond to lidar retrieved cloud base height. Squares represent PBL heights calculated from radiosonde meteorological profiles.

weakening of the penetrative convection, induced by the solar eclipse. After the end of the eclipse, entrainment zone thickness reached an almost constant value of $60 \mathrm{~m}$.

In Fig. 1b, the evolution of the ML height over Athens is shown. In this case measurements were performed within the time interval 09:00-13:10 UTC (84\% sun obscuration). ML heights below $250 \mathrm{~m}$ would not been detected by NTUA's lidar due to laser beam and telescope field-of-view overlap limitations (Chourdakis et al., 2002). At the beginning of the phenomenon, the ML height over Athens was found at 800 $\mathrm{m}$ and the entrainment zone had a thickness of $100 \mathrm{~m}$. After a constant fall between 09:30 and 10:50 UTC, the ML height reaches a value of $700 \mathrm{~m}$ at the maximum of the eclipse, while the thickness of the entrainment zone exhibits its minimum value of $30 \mathrm{~m}$. From 10:50 to 12:04 UTC (end of eclipse), the ML height continued to fall, reaching a value of $620 \mathrm{~m}$, while the entrainment zone thickness increased to $60 \mathrm{~m}$.

3.2 Discussion of the PBL evolution from lidar and meteorological measurements

The PBL generally forms due to heating of the Earth's surface. During the solar eclipse the gradual decrease of the Sun's radiation influences the surface heat fluxes and the boundary layer temperatures. In order to explain the evolution of the ML height as revealed by lidar measurements, we present time-series of the measured surface wind speed and air temperature at Thessaloniki (a) and Athens (b), respectively (Fig. 2). Figure 2a shows that relatively low wind-speed values prevailed during the hours preceding the eclipse. At Athens, the surface wind speed ranged between $2-6 \mathrm{~m} \mathrm{~s}^{-1}$ while at Thessaloniki between $0.5-2.5 \mathrm{~m} \mathrm{~s}^{-1}$. A further decrease of wind speed near mid-eclipse is observed at both sites, retaining low values until the end of the event and recovering after. At the same time, temperatures gradually fell with the evolution of the event and rose again during the recovery phase (Fig. 2b). In particular, at Thessaloniki, the surface temperature decreased by about $4^{\circ} \mathrm{C}$ between the first contact and the maximum of the eclipse, while for Athens the corresponding temperature fall was in the order of $2.5^{\circ} \mathrm{C}$ (Founda et al., 2007).

Additional meteorological measurements, namely analytical radiosonde data of potential temperature, relative humidity (RH) and wind speed with a vertical resolution of approximately $5 \mathrm{~m}$ are presented in Fig. 3. The radiosonde data from the Macedonia Airport of Thessaloniki launched at 11:55 UTC (Fig. 3a), indicate humid conditions with RH between $80-90 \%$ inside the PBL. The PBL height is estimated from the potential temperature profile, which indicates a clear inversion at $350 \mathrm{~m}$, coinciding with an inflection point in the profile of the relative humidity. The wind-speed profile (Fig. 3a) shows weak winds inside the PBL, in the range $2.5-4.5 \mathrm{~m} \mathrm{~s}^{-1}$. Radiosonde data available at Athens at 09:38 and 12:03 UTC (Fig. 3b) indicate less humid conditions, with RH lower than $60 \%$ up to $1000 \mathrm{~m}$. Launching times coincide with the start and the end of the eclipse. PBL heights calculated by the potential temperature profiles were approximately 400 and $220 \mathrm{~m}$ at 09:38 and 12:03 UTC respectively.

The PBL heights over Thessaloniki and Athens derived from the radiosondes profiles are also presented in Fig. 1. Radiosonde measurements in Athens were performed at Ellinikon Airport, located nearby the coast of the city and at a distance of $11.3 \mathrm{~km}$ from the lidar station (220 m a.s.1.), thus not being representative for Athens case. For this reason, the PBL height that one should expect for Athens lidar station is also represented by red squares in Fig. 1b. This 

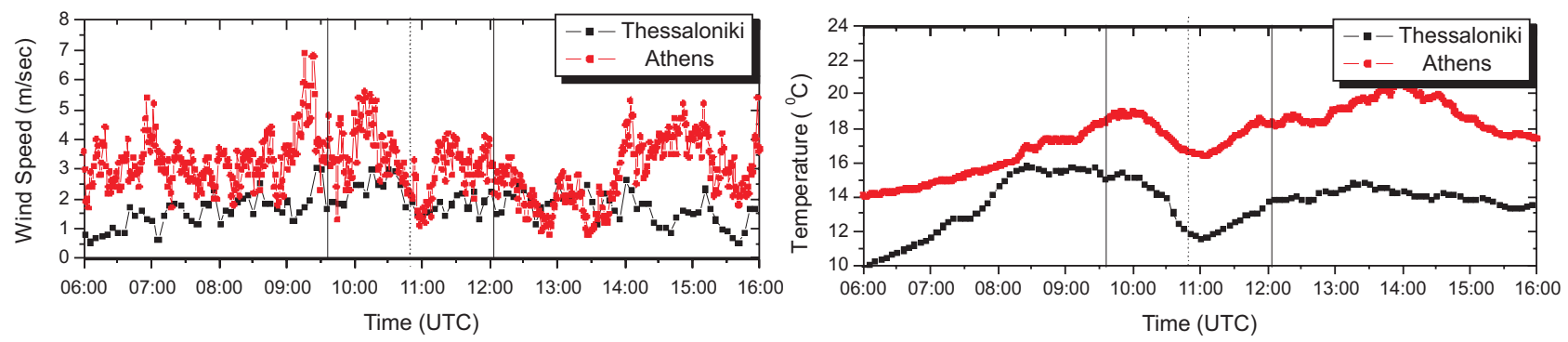

Fig. 2. Surface wind speed (a) and temperature (b) timeseries for Thessaloniki (black dotted line) and Athens (red dotted line).

PBL height is estimated by the radiosonde profile plus $220 \mathrm{~m}$, since the relatively gentle slope of the topographic surface is expected to displace upwards the boundary layer (Stull, 1988). In order to explain the evolution of the ML height as this was followed by lidar measurements, we will analyse the lidar estimates in conjunction with the meteorological observations for both sites. At Thessaloniki, the almost clear sky conditions and low wind-speed values (Fig. 2a, squares) prevailing during the pre-eclipse hours, are expected to lead to free convective conditions. Since the beginning of the eclipse occurred almost at local noon, a well mixed layer is expected to have formed by that time. After the first contact, incoming solar radiation progressively decreases and so does surface temperature, although with some delay due to thermal inertia of the atmosphere-land-sea system. As already mentioned, the amplitude of temperature drop at Thessaloniki was about $4.0^{\circ} \mathrm{C}$ while the minimum temperature occurred $12 \mathrm{~min}$ after the total phase of the eclipse (Founda et al., 2007). According to the lidar signal (Fig. 1a), at the beginning of the event, the convective mixed layer extends up to $\sim 700 \mathrm{~m}$ a.s.l. at Thessaloniki area. At the early stages of the eclipse, radiative cooling starts to take place near the surface in a similar way that surface cools after sunset. At that time the atmosphere is still mixed and temperature deficit extends from the surface at higher levels throughout the whole boundary layer due to turbulence mixing, resulting to the decrease of the ML height (Vogel et al., 2001). As evident from the lidar signal (Fig. 1a) at 10:15 UTC the ML height has decreased by about $200 \mathrm{~m}$. As eclipse approaches to the maximum phase, a pronounced temperature deficit is observed (Fig. 2b) and stable stratification is reached near the surface. Convectional mechanism is expected to weaken and eventually break down and heat transfer is confined to a thinner layer above ground. Aerosol tracers injected in the atmosphere are now dispersed between the surface and the new temperature inversion height $(200 \mathrm{~m})$. Due to the stabilization of the air at lower levels and the suppression of turbulent mechanisms, the conditions at higher levels remain relatively unchanged and this is also exhibited clearly in Fig. 1a, where the structure of the initial mixed layer remains almost unaltered after 10:20 UTC. This behaviour resembles the one observed during night-time where the so called Residual Layer coexists
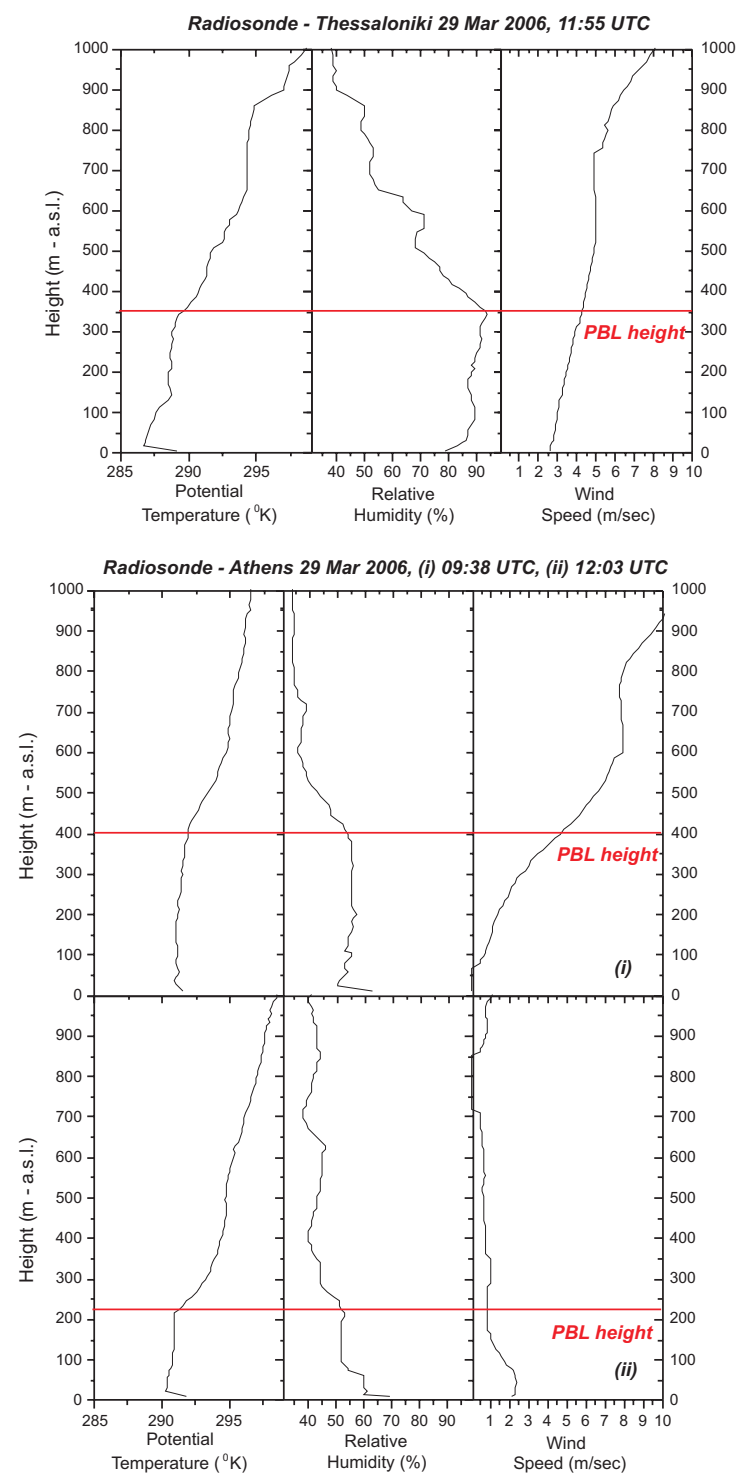

Fig. 3. Potential Temperature, relative humidity and wind speed measured with radiosondes on 29 March 2006, at 11:55 UTC for Thessaloniki (a) and at 09:38 UTC (b-top panel-i) and 12:03 UTC for Athens (b-bottom panel-ii). 


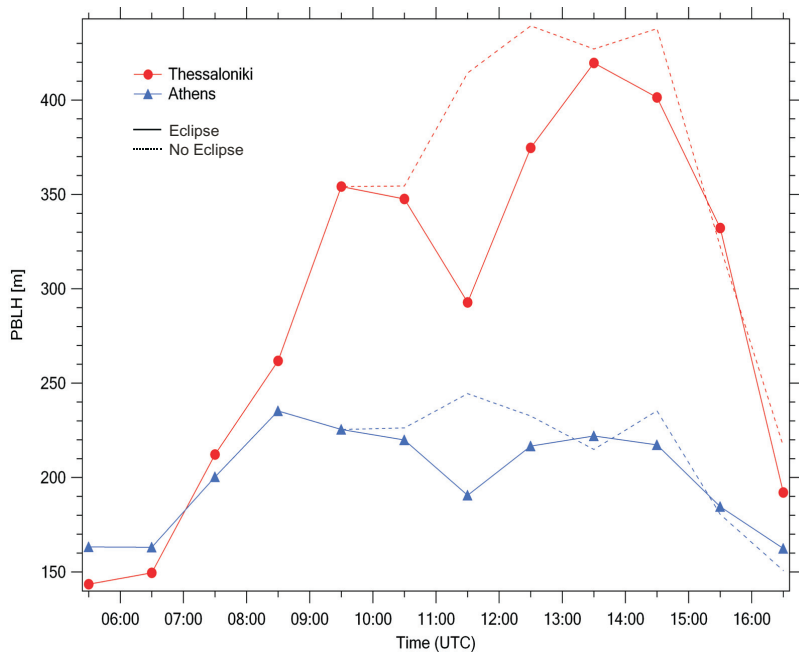

Fig. 4. PBL height as diagnosed by CAMx for Thessaloniki and Athens. Dashed lines correspond to control runs without eclipse.

with the nocturnal boundary layer.

Another important observation that supports our arguments is the variation of the amplitude of the entrainment zone. It is obvious from Fig. 1a that the thickness of this zone is reduced near the maximum phase of the eclipse, indicating the suppression of turbulence mechanisms and the weakening of the penetrative convection at that time. The weakening of the mixing processes due to the cooling of the atmosphere is also reflected in the surface wind speed (Fig. 2a) which decreases near mid-eclipse and retains low values until the end of the event. Between 11:00 and 11:50 UTC when clouds were observed over Thessaloniki, one can see in Fig. 1a (red triangles) that the lidar retrieved cloud base height shows a positive trend. According to Stull (1988), in presence of clouds, the PBL height is defined as the cloud base height. After 11:00 UTC surface air temperature starts to recover (Fig. 2b) although it does not recover to its pre-eclipse value, mainly due to the time of the day and the increased cloud cover. We indicate that for the time period between 11:00 and 11:50 UTC, the height of the inversion base is increasing due to the surface temperature recovery and this argument is supported by the height of the layer at $200 \mathrm{~m}$ on 11:00 UTC, followed by the increase of the cloud base height. According to radiosonde data at 11:55 UTC (Fig. 3a), the structure of the upper part of the PBL indicates a slight stability, however it is expected that eddies transfer heat and momentum, mixing again the boundary layer. After 11:50 UTC when the eclipse approximately ended, the ML height was found at $600 \mathrm{~m}$ and that height was approximately retained until 12:50 UTC.

The effect of the thermal inertia of the atmosphere-landsea system in surface temperature response due to the eclipse seems to be more pronounced in Athens area. According to observations performed in the centre of Athens (Fig. 2b), surface air temperature at $1.5 \mathrm{~m}$ a.s.l. retained its increas- ing march after the beginning of the event, while the time shift of temperature drop from the first contact was of the order of 30 min (Founda et al., 2007). This is partly attributed to the higher (compared to Thessaloniki) wind speeds which prevailed in Athens (Fig. 2a) area resulting to the mixing of the air and other local factors, like cloudiness that preceded the eclipse (Founda et al., 2007). High values of incoming short wave radiation and moderate wind speeds in Athens contributed to the formation of a well mixed boundary layer by the beginning of the event, as is also evident from radiosonde data at 09:38 UTC (Fig. 3b, i). According to the lidar signal (Fig. 1b) the mixed layer extends up to the height of $800 \mathrm{~m}$ a.s.l. at 09:30 UTC. The delay in surface air cooling observed in Athens area is reflected to the height of the mixed layer which decreases at a slower rate compared to Thessaloniki for about one hour after the first contact as evident in Fig. 1b. Then the height of the mixed layer starts to decrease faster for the reasons already explained in Thessaloniki case. The formation of a lower stable layer extending from the ground to the height of $410 \mathrm{~m}$ is also observed in Athens for a short period near the maximum phase of the eclipse.

The smaller amplitude of temperature drop and higher surface wind speeds in Athens have possibly contributed to less stable (compared to Thessaloniki) atmospheric conditions near the surface. This is also supported from the radiosonde data at the two sites near the end of the eclipse in Fig. 3a and $3 \mathrm{~b}$-ii. The potential temperature gradient in the layers $23-220 \mathrm{~m}$ at Athens and $23-350 \mathrm{~m}$ at Thessaloniki were 0.6 and $0.8^{\circ} \mathrm{C} / 100 \mathrm{~m}$ respectively, suggesting greater stability at Thessaloniki. Under these conditions surface temperature deficit is transferred at higher levels resulting to the cooling of the entire mixing layer and its depression. Finally, due to thermal inertia of the air and the natural decrease of solar elevation after the eclipse, mixing layer height does not regain its initial value for Athens.

\subsection{Modeling}

Figure 4 shows the PBL height as diagnosed by CAMx process analysis in Thessaloniki and Athens (lines with markers). An additional run has been performed in order to simulate the atmospheric processes without eclipse (dashed lines). At both sites the PBL height is approximately $150 \mathrm{~m}$ at 06:00 UTC and gradually increases to reach a maximum four hours later. Normally, the PBL should continue to develop in order to reach its maximum height early afternoon hours as indicated by the dashed lines. However after 09:30 UTC the eclipse starts to affect the PBL height. Due to vertical turbulent mixing decay PBL decreases and reaches a local minimum at around 11:30 UTC i.e. during the eclipse maximum. Two hours later the PBL height has almost fully recovered and starts to decrease gradually again after 15:00 UTC as the sun slowly sets. Interestingly the PBL height in Thessaloniki is on average higher than in Athens. This is 

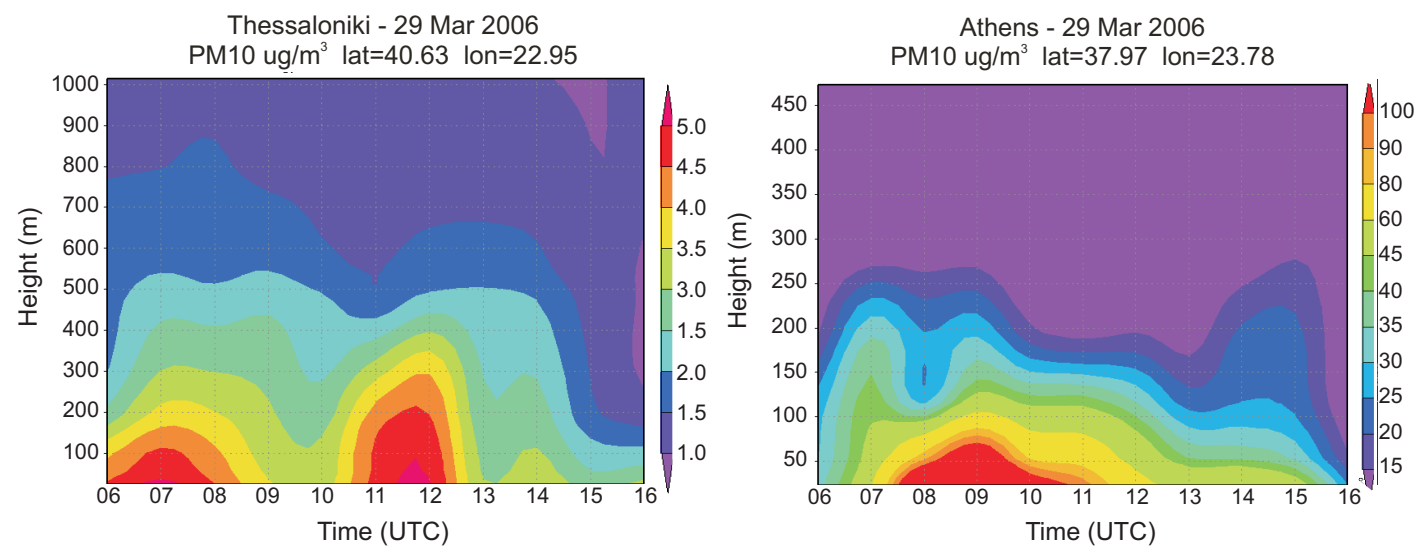

Fig. 5. Time slice of vertical particulate matter (PM) distribution at the two measuring stations, Thessaloniki (top panel) and Athens (bottom panel).

also supported by the radiosonde measurements which indicate that at $\sim 12: 00$ UTC the PBL height at Thessaloniki is appreciably higher than the respective over Athens. During sunrise the PBL height in Thessaloniki reaches up to $350 \mathrm{~m}$, while in Athens only to $225 \mathrm{~m}$. During the maximum of the eclipse, the PBL height falls down to $290 \mathrm{~m}$ and $190 \mathrm{~m}$ in Thessaloniki and Athens, respectively. If the eclipse had not taken place the PBL heights would have reached 440 and $245 \mathrm{~m}$, respectively, during the period 12:00-15:00 UTC.

Another interesting feature giving insight to the PBL evolution during the eclipse is the time slice of vertical PM distribution. The vertical profile of PM concentrations is basically dominated by two factors: ground emissions and turbulent mixing. As clearly depicted in Fig. 5, emissions injected mostly between 06:00-12:00 UTC, control the PM concentration levels in the first $100 \mathrm{~m}$. For altitudes higher than $100 \mathrm{~m}$, vertical mixing is the dominant factor over pollutant concentrations. If PM is to be used as a qualitative index of the PBL evolution, it can be noticed that the basic patterns observed in Fig. 4 can be also noted in Fig. 5. After 06:00 UTC particulate matter trapped in lower levels is transported upwards, a clear indication of the PBL expansion. However vertical transport does not appear to evolve undisturbed by reaching a maximum at early afternoon hours, on the contrary it decays during the eclipse. For a constant altitude between 200 and $300 \mathrm{~m}$ at both sites, PM concentrations are higher before and after the eclipse and fall somewhat during the event.

We have to mention that $\mathrm{PM}_{10}$ vertical distribution is used in this paper only as a qualitative index of the evolution of the boundary layer therefore Fig. 5 cannot be used as a quantitative index of the ML height and thus cannot be directly compared to Lidar ML height measurements. The diagnostic calculation of PBL height by CAMx on the other hand (Fig. 4), yields indeed a PBL height which is generally lower than what is measured. According to our findings, a good agreement between lidar measurements and model estima- tions was found in the overall behavior of the PBL but not in absolute numbers. Possible reason for this discrepancy is that the lidar measures on a spot while the model averages in an area of $4 \mathrm{~km}^{2}$. Additionally, the model produces only hourly average data while measurements have a sampling time of few minutes.

Finally, we use $\mathrm{CO}$ as an additional tracer for PBL evolution. In Fig. 6, the evolution of $\mathrm{CO}$ vertical profile is shown from 08:30 to 16:30 UTC, for the non-eclipse model run (top panel). During the early morning hours (08:30-10:30 UTC), ground $\mathrm{CO}$ concentrations increase in the lower levels with time due to increasing emissions. A negative vertical gradient above indicates that there is not sufficient turbulent mixing yet to homogenize pollutant concentrations. Later, the PBL is gradually developing and reaches up to $450 \mathrm{~m}$ until 12:30 UTC as indicated by the constant CO mixing ratios. The negative gradient remains for altitudes higher than $450 \mathrm{~m}$. It is noticeable that Figs. 4 and 6 compare well concerning the PBL height which is derived with two different methods: CAMx diagnosed and indirectly using $\mathrm{CO}$ as a tracer of the PBL evolution. For the three consecutive hours (14:30-16:30 UTC) CO values remain almost unchanged to the whole range of altitude justifying the assumption of a well developed PBL. The bottom panel shows model results, for a run with eclipse parameterizations. Differences are obvious during the $2 \mathrm{~h}$ span 09:30-11:30 UTC. A negative CO vertical gradient remains until the end of eclipse implying a poorly developed PBL, while the 12:30 UTC curve indicate a homogenized layer that extends only up to $200 \mathrm{~m}$. The comparisons of CO vertical profiles after 14:30 UTC with eclipse and no-eclipse parameterizations, which are almost identical, imply that after two hours the atmosphere has recovered from the eclipse "disturbance". 

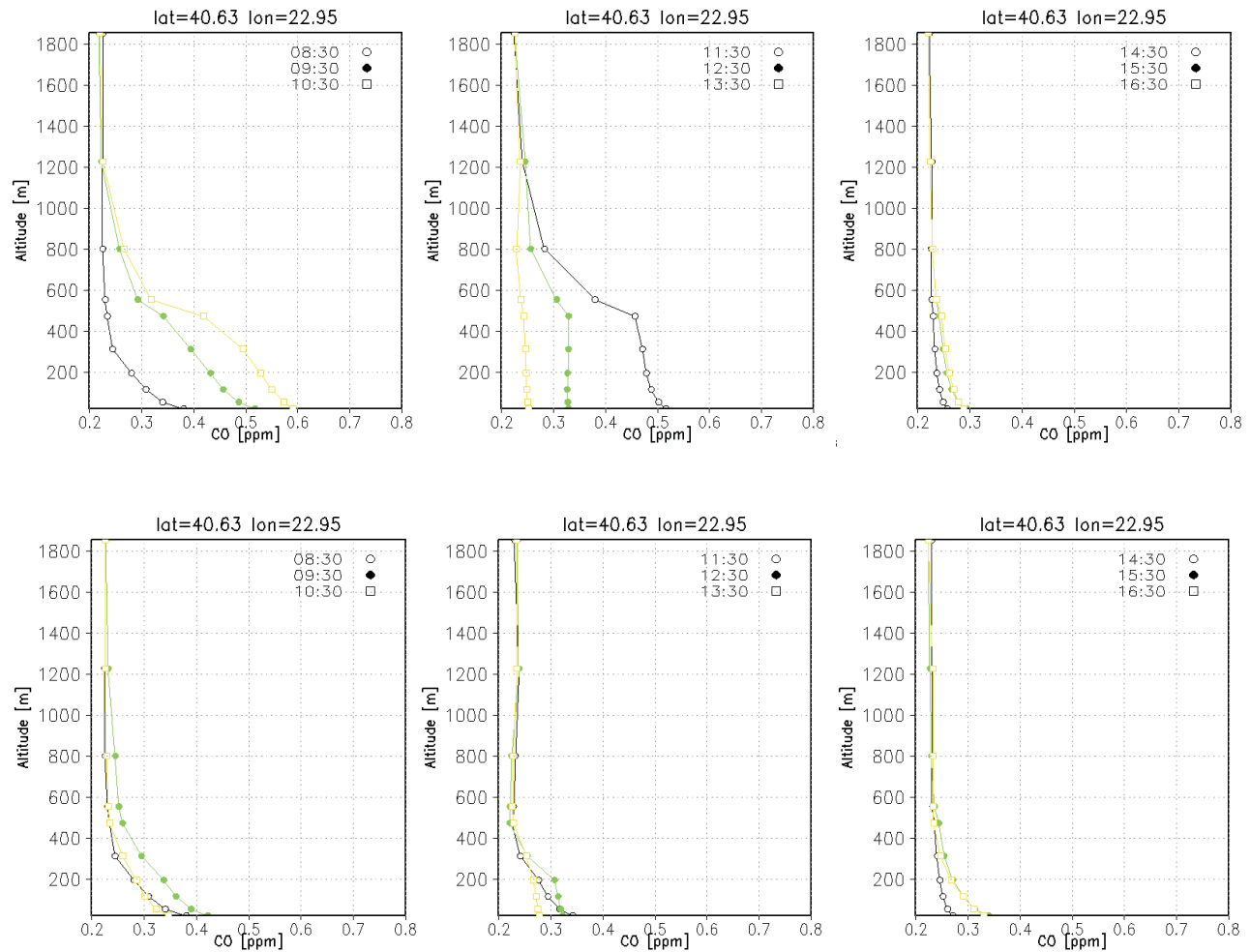

Fig. 6. Temporal evolution of modeled $\mathrm{CO}$ vertical profiles for the eclipse (bottom panel) and non-eclipse case (top panel) for the site in Thessaloniki.

\section{Summary and conclusions}

Several effects consistent with the rapid cut-off and turn-on of solar radiation were observed in the planetary boundary layer during the 29 March 2006, solar eclipse at Greece by the use of lidar backscatter methods. As expected, the eclipse primarily influenced the surface meteorological parameters. However, from the lidar data presented here, it becomes clear that the influence of the eclipse is extended up to the height of the mixing layer. The thickness of the entrainment zone exhibits its minimum during the maximum of the eclipse indicating the suppression of turbulence mechanisms at that time. A ground layer with height of $200 \mathrm{~m}$ for Thessaloniki and $410 \mathrm{~m}$ for Athens was formed around the maximum of the eclipse due to the stabilization of the air at lower levels. The elevated temperature inversion was responsible for the suppression of convectional mixing and the formation of a residual aerosol layer for Thessaloniki, where the inversion was stronger.

In this study we used both $\mathrm{CO}$ and PM as tracers for the PBL height. In order to further investigate the eclipse effects on the atmospheric dynamics, a second run was performed, without introducing the eclipse parameterizations. The results exhibit clear differences in PBL height and structure for both Athens and Thessaloniki. Model diagnosed PBL height decrease during the solar eclipse due to vertical transport decay, in agreement with the experimental findings. Moreover, the vertical profiles of atmospheric particles and gaseous species showed vertical mixing attenuation.

Acknowledgements. EG and RM acknowledge the support of the PENED 2003 project. The project is co-financed $75 \%$ of public expenditure through EC - European Social Fund and 25\% of public expenditure through Ministry of Development, General Secretariat of Research and development (Project 03-ED-169) and through private sector (Raymetrics SA.), under Measure 8.3 of OPERATIONAL PROGRAMME "COMPETITIVENESS" in the 3rd Community Support Programme. Radiosonde data were provided by the Hellenic Meteorological Service (HNMS). Meteorological surface measurements were kindly provided by T. Karacostas (Department of Meteorology - Aristotle University of Thessaloniki). AM acknowledges S. Kazadzis for the helpful conversation regarding radiation issues.

Edited by: N. Mihalopoulos

\section{References}

Amiridis, V., Balis, D. S., Kazadzis, S., Bais, A., Giannakaki, E., Papayannis, A., and Zerefos, C.: Four-year aerosol observations with a Raman lidar at Thessaloniki, Greece, in the framework of European Aerosol Research Lidar Network (EARLINET), J. Geophys. Res., 110, D21203, doi:10.1029/2005JD006190, 2005. 
Antonia, R. A., Chambers, A. J., Phong-Anant, D., Rajagopalan, S., and Sreenivasan, K. R.: Response of atmospheric surface layer turbulence to a partial solar eclipse, J. Geophys. Res., 4, 1689$1692,1979$.

Arulraj, S., Dharmaraj, T., Debaje, S. B., Badgavanth Singh, A., and Vernekar, K. G.: The dynamics of the surface layer during total solar eclipse 1995, Mausam, 49, 475-480, 1998.

Balis, D., Amiridis, V., Zerefos, C., and Papayannis, A.: Verification of the experimental determination of the lidar overlap profile by a Raman lidar, Lidar Remote Sensing in Atmospheric and Earth Sciences, 21th International Laser Radar Conference (ILRC21), 125-128, 2002.

Balis, D., Papayannis, A., Galani, E., Marenco, F., Santacesaria, V., Hamonou, E., Chazette, P., Ziomas, I., and Zerefos, C.: Tropospheric LIDAR aerosol measurements and sun photometric observations at Thessaloniki, Greece, Atmos. Environ., 34, 925932, 2000.

Böckmann, C., Wandinger, U., Ansmann, A., Bösenberg, J., Amiridis, V., Boselli, A., Delaval, A., De Tomasi, F., Frioud, M., Grigorov, I., Hagard, A., Horvat, M., Iarlori, M., Komguem, L., Kreipl, S., Larcheveque, G., Matthias, V., Papayannis, A., Pappalardo, G., Rocadenbosch, F., Rodrigues, J. A., Schneider, J., Shcherbakov, V., and Wiegner, M.: Aerosol lidar intercomparison in the framework of the EARLINET project: Part II Aerosol backscatter algorithms, Appl. Opt., 43, 977-989, 2004.

Chourdakis, G., Papayannis, A., and Porteneuve, J.: Analysis of the receiver response for a noncoaxial lidar system with fiber-optic output, Appl. Opt., 41, 2715-2723, 2002.

Dolas, P. M., Ramachandran, R., Sen, Gupta, K., Patil, S. M., and Jadhav, P. N.: Atmospheric surface layer processes during the total solar eclipse of 11 August 1999, Boundary Layer Meteorol., 104, 445-461, 2002.

Eaton, F. D., Hines, J. R. , Hatch, W. H., Cionco, R. M., Byers, J., and Garvey, D.: Solar eclipse effects observed in the planetary boundary layer over a desert, Boundary Layer Meteorol., 83, 331-346, 1997.

Flamant, C., Pelon, J., Flamant, P., and Durand, P.: Lidar determination of the entrainment zone thickness at the top of the unstable marine atmospheric boundary layer, Boundary Layer Meteorol., 83, 247-284, 1997.

Founda, D., Melas, D., Lykoudis, S., Lisaridis, I., Gerasopoulos, E., Kouvarakis, G., Petrakis, M., and Zerefos, C.: The effect of the total solar eclipse of 29 March 2006 on meteorological variables in Greece, Atmos. Chem. Phys. Discuss., 7, 10 631-10 667, 2007

Gerasopoulos, E., Zerefos, C. S., Tsagouri, I., et al.: The Total Solar Eclipse of March 2006: Overview, Atmos. Chem. Phys. Discuss., 7, 17 663-17 704, 2007.

Girard-Ardhuin, F., Bénech, B., Campistron, B., Dessens, J., and Jacoby-Koaly, S.: Remote Sensing and surface observations of the response of the Atmospheric Boundary Layer to a Solar Eclipse, Boundary Layer Meteorol., 106, 93-115, 2003.

Kolev, N., Tatarov, B., Grigorieva, V., Donev, E., Simenonov, P., Umlensky, V., Kaprielov, B., and Kolev, I.: Aerosol Lidar and in situ ozone observations of the planetary boundary layer over Bulgaria during the solar eclipse of 11 August 1999, Int. J. Remote Sens., 26, 3567-3584, 2005
Matthias, V., Freudenthaler, V., Amodeo, A., Balin, I., Balis, D., Bösenberg, J., Chaikovsky, A., Chourdakis, G., Comeron, A., Delaval, A., De Tomasi, F., Eixmann, R., Hågård, A., Komguem, L., Kreipl, S., Matthey, R., Rizi, V., Rodrigues, J. A., Wandinger, U., and Wang, X.: Aerosol Lidar Intercomparison in the Framework of the EARLINET Project. 1. Instruments, Appl. Opt., 43, 961-976, 2004.

Menut, L., Flamant, C., Pelon, J., and Flamant, P.: Urban boundary layer height determination from lidar measurements over the Paris area, Appl. Opt., 38, 945-954, 1999.

Narasimha, R., Prabhu, A., Narahari Rao, K., and Prasad, C. R.: Atmospheric Boundary Layer Experiment, Proc. of INSA Bull., 48, 175-186, 1982.

Papayannis, A. and Chourdakis, G.: The EOLE project: a multiwavelength laser remote sensing (lidar) system for ozone and aerosol measurements in the troposphere and the lower stratosphere. Part II: Aerosol measurements over Athens, Greece, Inter. J. Rem. Sens., 23, 179-196, 2002.

Pappalardo, P., Amodeo, A., Wandinger, U., Matthias, V., Bösenberg, J., Alpers, M., Amiridis, V., de Tomasi, F., Frioux, M., Iarlori, M., Komguen, L., Larcheveque, G., Papayannis, A., Schumacher, R., and Wang, X.: Aerosol lidar intercomparison in the framework of the EARLINET project. 3. Raman lidar algorithm for aerosol extinction, backscatter and lidar ratio, Appl. Opt., 43, 5370-5385, 2004.

Poupkou, A., Symeonidis, P., Lisaridis, I., Pouspourika, E., Yay, O. D., Melas, D., Ziomas, I., Balis, D., and Zerefos, C.: Compilation of an emission inventory for the purpose of studying the regional photochemical pollution in the Balkan Region, Proceedings of the Quadrennial Ozone Symposium 2004, 902-903, 2004.

Sethuraman, S.: Dynamics of the atmospheric boundary layer during the 1980 total solar eclipse, Proceedings of INSA, 48, 187$195,1982$.

Stull, R. B.: An Introduction to Boundary Layer Meteorology, Kluwer Academic Publishers, Dordrecht, The Netherlands, 1988.

Vogel, B., Baldauf, M., and Fielder, F.: The influence of a solar eclipse on temperature and wind in the Upper-Rhine Valley - A numerical case study, Meteorol. Z., 10, 207-214, 2001.

Zanis, P., Katragkou, E., Kanakidou, M., Psiloglou, B., Karathanasis, S., Vrekoussis, M., Gerasopoulos, E., Lysaridis, I., Markakis, K., Poupkou, A., Amiridis, V., Melas, D., Mihalopoulos, N., and Zerefos, C.: Effects on surface atmospheric photo-oxidants over Greece during the total solar eclipse event of 29 March 2006, Atmos. Chem. Phys. Discuss., 7, 11 399-11 428, 2007. 